\title{
Sintesis $\mathrm{Bi}_{4} \mathrm{Ti}_{3} \mathrm{O}_{12}$ Terdoping Vanadium dengan Metode Lelehan Garam Tunggal NaCl
}

\section{The Moltens Salt Synthesis of Vanadium Doped $\mathrm{Bi}_{4} \mathrm{Ti}_{3} \mathrm{O}_{12}$ using Single Salt $\mathrm{NaCl}$}

\author{
Khawiyatur Riv'ah Agustina ${ }^{1}$, Dwi Suheriyanto ${ }^{2}$, Anton Prasetyo ${ }^{1 *}$ \\ ${ }^{1}$ Program Studi Kimia, Fakultas Sains dan Teknologi, Universitas Islam Negeri Maulana Malik Ibrahim Malang, \\ Jalan Gajayana 50 Malang, 65144, Indonesia \\ ${ }^{2}$ Program Studi Biologi, Fakultas Sains dan Teknologi, Universitas Islam Negeri Maulana Malik Ibrahim \\ Malang, Jalan Gajayana 50 Malang, 65144, Indonesia \\ *E-mail: anton@kim.uin-malang.ac.id
}

DOI: https://doi.org/10.26874/jkk.v3i1.50

Received: 19 May 2020, Revised: 31 May 2020, Accepted: 31 May 2020, Online: 31 May 2020

\begin{abstract}
Abstrak
$\mathrm{Bi}_{4} \mathrm{Ti}_{3} \mathrm{O}_{12}$ merupakan senyawa Aurivillius lapis 3 yang berpotensi sebagai material fotokatalis dengan energi celah pita $2,9 \mathrm{eV}(427 \mathrm{~nm})$. Untuk memperluas pemanfaatannya, maka energi celah harus diturunkan. Salah satu usaha untuk menurunkan energi celah pita adalah dengan teknik pendopingan logam. Dalam penelitian ini, kami melakukan pendopingan logam vanadium pada $\mathrm{Bi}_{4} \mathrm{Ti}_{3} \mathrm{O}_{12}\left(\mathrm{Bi}_{4} \mathrm{Ti}_{3-}\right.$ ${ }_{x} \mathrm{~V}_{x} \mathrm{O}_{12}(x=0,0,05 ; 0,1 ; 0,15$, dan 0,2$\left.)\right)$ dengan metode lelehan garam. Data difraktogram menunjukkan fasa $\mathrm{Bi}_{4} \mathrm{Ti}_{3} \mathrm{O}_{12}$ terbentuk dengan fasa pengotor $\mathrm{BiNaO}_{3}$ dan $\mathrm{NaV}_{6} \mathrm{O}_{11}$. Hasil karakterisasi dengan menggunakan Scanning Electron Microscopy (SEM) menunjukkan bahwa bentuk partikel $\mathrm{Bi}_{4} \mathrm{Ti}_{3} \mathrm{O}_{12}$ adalah plate-like. Hasil karakterisasi dengan menggunakan ultraviolet (UV)-visible (Vis) Diffuse Reflectance Spectroscopy (UV-Vis DRS) menunjukkan bahwa sampel yang diperoleh mempunyai energi celah pita yang lebih rendah dibandingkan dengan $\mathrm{Bi}_{4} \mathrm{Ti}_{3} \mathrm{O}_{12}$
\end{abstract}

Kata kunci: $\mathrm{Bi}_{4} \mathrm{Ti}_{3} \mathrm{O}_{12}$, dopant vanadium, energi celah

\section{Abstract}

$\mathrm{Bi}_{4} \mathrm{Ti}_{3} \mathrm{O}_{12}$ is one of member threelayer Aurivillius compound family, which has the potential as a photocatalyst material with band gap energy $2.9 \mathrm{eV}(427 \mathrm{~nm})$. Therefore, to expand its utilization, the gap energy must be reduced. Doping with metal is one technique that can reduce the energy of a band gap. In this study, we synthesized vanadium doped $\mathrm{Bi}_{4} \mathrm{Ti}_{3} \mathrm{O}_{12}\left(\mathrm{Bi}_{4} \mathrm{Ti}_{3-x} \mathrm{~V}_{x} \mathrm{O}_{12}(x=0,0.05 ; 0.1 ; 0.15\right.$ and 0.2) by molten salt synthesis. Difractogram data shows that the $\mathrm{Bi}_{4} \mathrm{Ti}_{3} \mathrm{O}_{12}$ phase is formed with $\mathrm{BiNaO}_{3}$ and $\mathrm{NaV}_{6} \mathrm{O}_{11}$ impurities. The image of SEM showed that the particle shape of $\mathrm{Bi}_{4} \mathrm{Ti}_{3} \mathrm{O}_{12}$ is plate like. $U V$-Vis DRS spectra showed that the vanadium doped $\mathrm{Bi}_{4} \mathrm{Ti}_{3} \mathrm{O}_{12}$ have lower band gap energy than $\mathrm{Bi}_{4} \mathrm{Ti}_{3} \mathrm{O}_{12}$.

Keywords: $\mathrm{Bi}_{4} \mathrm{Ti}_{3} \mathrm{O}_{12}$, dopant vanadium, band gap energy

\section{Pendahuluan}

Perkembangan industri tekstil yang pesat menyebabkan meningkatnya limbah zat warna seperti Rhodamin B, metil oranye, metilen biru dan zat warna tekstil lainnya. Beberapa metode penanganan limbah zat warna telah dikembangkan antara lain metode adsorpsi, lumpur aktif, bioremediasi, koagulasi, filtrasi membran, elektrolisis dan fotokatalisis. Metode fotokatalisis dianggap sebagai metode yang sangat berpotensi dalam mendegradasi zat warna dengan produk akhir yang ramah lingkungan [1].

Senyawa $\mathrm{Bi}_{4} \mathrm{Ti}_{3} \mathrm{O}_{12}$ merupakan material semikonduktor yang memiliki energi celah pita $\left(E_{g}\right)$ sebesar 2,9 eV $(427 \mathrm{~nm})$ dan laju rekombinasi yang tinggi [2]. Hal ini menunjukkan bahwa 
energi yang dibutuhkan masih relatif tinggi. Untuk menurunkan energi celah pita yang tinggi sehingga dapat meningkatkan kinerja fotokatalitik dapat digunakan beberapa metode seperti doping dengan kation atau anion, dimodifikasi dengan logam mulia, atau berkomposisi dengan semikonduktor lain [1]. Beberapa logam telah dilaporkan digunakan untuk mendoping senyawa $\mathrm{Bi}_{4} \mathrm{Ti}_{3} \mathrm{O}_{12}$ di antaranya adalah $\mathrm{Fe}, \mathrm{Cr}$, dan $\mathrm{V}$ [2-5]. Gu dkk. (2017) melaporkan $\mathrm{Bi}_{4} \mathrm{Ti}_{3} \mathrm{O}_{12}$ didoping vanadium dengan variasi doping $(x=0 ; 0,05 ; 0,1)$. Sintesis dilakukan dengan metode hidrotermal dan diperoleh hasil bahwa ditemukan penurunan energi celah pita yang lebih kecil [5]. Hal ini menunjukkan bahwa logam vanadium berpotensi digunakan sebagai dopan.

Aktivitas fotokatalitik dipengaruhi oleh banyak faktor yang salah satunya adalah morfologi partikel [6]. Metode lelehan garam adalah suatu metode yang sederhana yang mempunyai beberapa keuntungan yaitu memerlukan suhu reaksi yang relatif rendah, mempunyai kemampuan untuk mengontrol ukuran/bentuk partikel [7]. Beberapa pihak telah melaporkan bentuk morfologi partikel senyawa $\mathrm{Bi}_{4} \mathrm{Ti}_{3} \mathrm{O}_{12}$ yang didoping dengan metode lelehan garam yaitu berbentuk plate-like [8,9]. Oleh karena itu, dalam penelitian ini dilakukan pendopingan material $\mathrm{Bi}_{4} \mathrm{Ti}_{3} \mathrm{O}_{12}\left(\mathrm{Bi}_{4} \mathrm{Ti}_{3-x} \mathrm{~V}_{x} \mathrm{O}_{12}(x=\right.$ $0,0,05 ; 0,1 ; 0,15$ dan 0,2$)$ ) dengan metode lelehan garam dengan tujuan mendapatkan senyawa $\mathrm{Bi}_{4} \mathrm{Ti}_{3} \mathrm{O}_{12}$ terdoping vanadium yang mempunyai morfolgi yang khas. Sampel yang diperoleh dikarakterisasi menggunakan difraksi sinar- $X$ (XRD), Scanning Electron Microscopy (SEM), dan UV-Vis DRS.

\section{Metode Penelitian}

Prekursor yang digunakan $\mathrm{Bi}_{2} \mathrm{O}_{3}$ (Aldrich, 99,9\% serbuk), $\mathrm{TiO}_{2}$ (Aldrich, 99,9\% serbuk), $\mathrm{V}_{2} \mathrm{O}_{3}$ (Sigma Aldrich), $\mathrm{NaCl}$ (Aldrich, 99,5\% serbuk), Aseton, $\mathrm{AgNO}_{3}$ dan akuades.

Sintesis $\mathrm{Bi}_{4} \mathrm{Ti}_{3-x} \mathrm{~V}_{x} \mathrm{O}_{12}(x=0 ; 0,05 ; 0,1$; $0,15 ; 0,2)$ dilakukan dengan cara mencampur prekursor $\mathrm{Bi}_{2} \mathrm{O}_{3}, \mathrm{TiO}_{2}$, dan $\mathrm{V}_{2} \mathrm{O}_{3}$, yang disesuaikan dengan perhitungan stoikiometri. Prekursor dihomogenkan dengan cara digerus menggunakan mortar agate selama 1 jam dan ditambahkan dengan aseton. Sampel kemudian dikalsinasi pada suhu $700^{\circ} \mathrm{C}$ selama 6 jam. Dengan cara yang sama dilakukan setelah sampel dikeluarkan dari tanur dan dipanaskan pada suhu $900^{\circ} \mathrm{C}$ selama 8 jam.
Sampel yang diperoleh dikarakterisasi menggunakan difraksi sinar- $X$ (XRD) pada rentang $2 \theta \quad\left({ }^{\circ}\right)=10-70$. Difraktogram sampel dicocokkan dengan standar yang terdapat pada Joint Committee on Powder Diffraction Standars (JCPDS) untuk mengetahui fasa yang terbentuk. Morfologi sampel dikarakterisasi menggunakan Scanning Electron Microscopy-Energy Dispersive $X$-Ray Spectroscopy. Energi celah dihitung dari data spektrum adsorpsi yang diukur pada rentang panjang gelombang 200-800 $\mathrm{nm}$.

\section{$3 \quad$ Hasil dan Diskusi}

Difraktogram senyawa $\mathrm{Bi}_{4} \mathrm{Ti}_{3-x} \mathrm{~V}_{x} \mathrm{O}_{12} \quad(x=$ $0,05 ; 0,1 ; 0,15 ; 0,2)$ ditampilkan pada Gambar 1 dan kemudian dicocokkan dengan JCPDS No. 73$2181\left(\mathrm{Bi}_{4} \mathrm{Ti}_{3} \mathrm{O}_{12}\right)$ dan diperoleh kemiripan, akan tetapi terdapat fasa pengotor yaitu senyawa $\mathrm{NaV}_{6} \mathrm{O}_{11}$ dan $\mathrm{BiNaO}_{3}$, fasa pengotor yang terbentuk dapat disebabkan karena reaksi antar prekursor $\mathrm{Bi}_{2} \mathrm{O}_{3}, \mathrm{~V}_{2} \mathrm{O}_{3}$ dan $\mathrm{NaCl}$ yang terjadi pada suhu tinggi $\left(900^{\circ} \mathrm{C}\right)$.

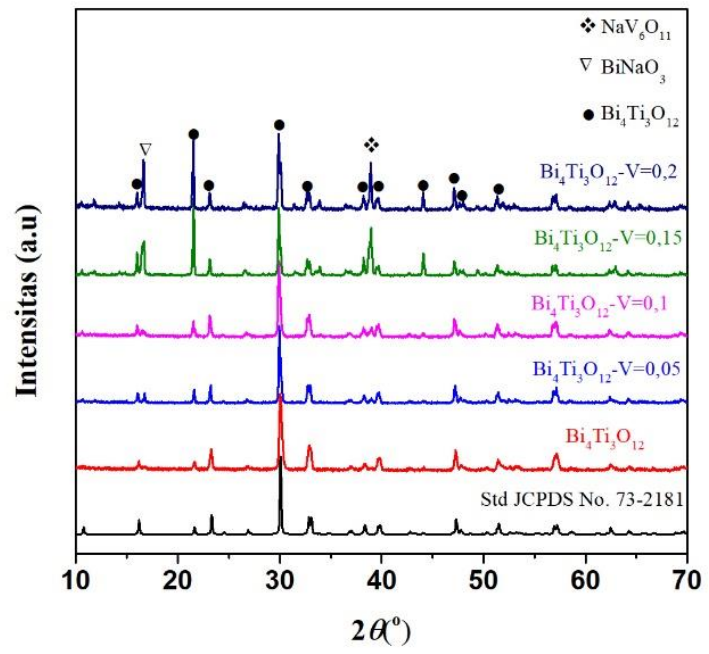

Gambar 1. Difraktogram senyawa $\mathrm{Bi}_{4} \mathrm{Ti}_{3} \mathrm{O}_{12}$ terdoping vanadium

Pergeseran puncak difraktogram pada $2 \theta\left({ }^{\circ}\right)=$ 30,1 yang ditampilkan pada Gambar 2 dan diketahui terjadi pergeseran posisi puncak yang mengindikasikan adanya perubahan nilai parameter kisi, sehingga terdapat kemungkinan bahwa logam vanadium menggantikan sebagian posisi $\mathrm{Ti}^{4+}$. 


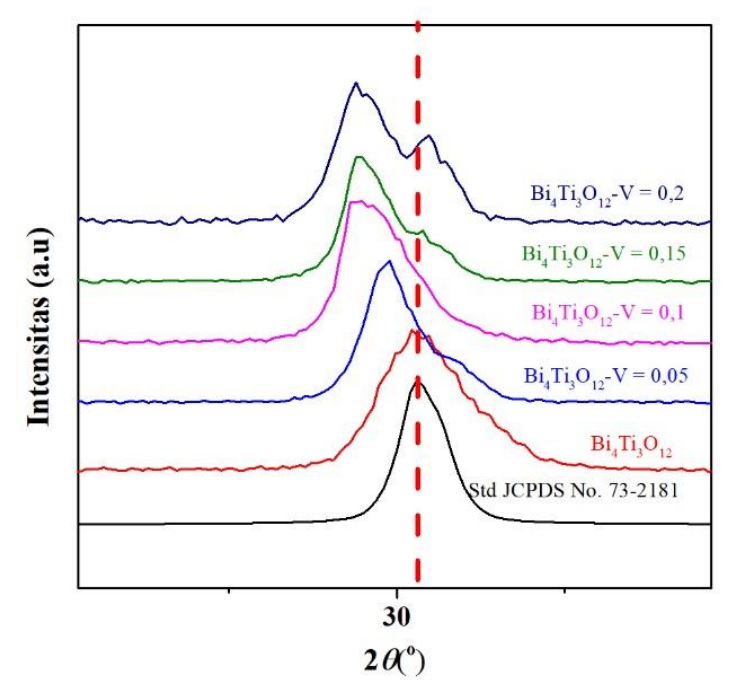

Gambar 2. Puncak difraktogram $\mathrm{Bi}_{4} \mathrm{Ti}_{3-x} \mathrm{~V}_{x} \mathrm{O}_{12}$ $(x=0,05 ; 0,1 ; 0,15 ;$ dan 0,2$)$ pada posisi $2 \theta\left(^{\circ}\right)=30,1$.

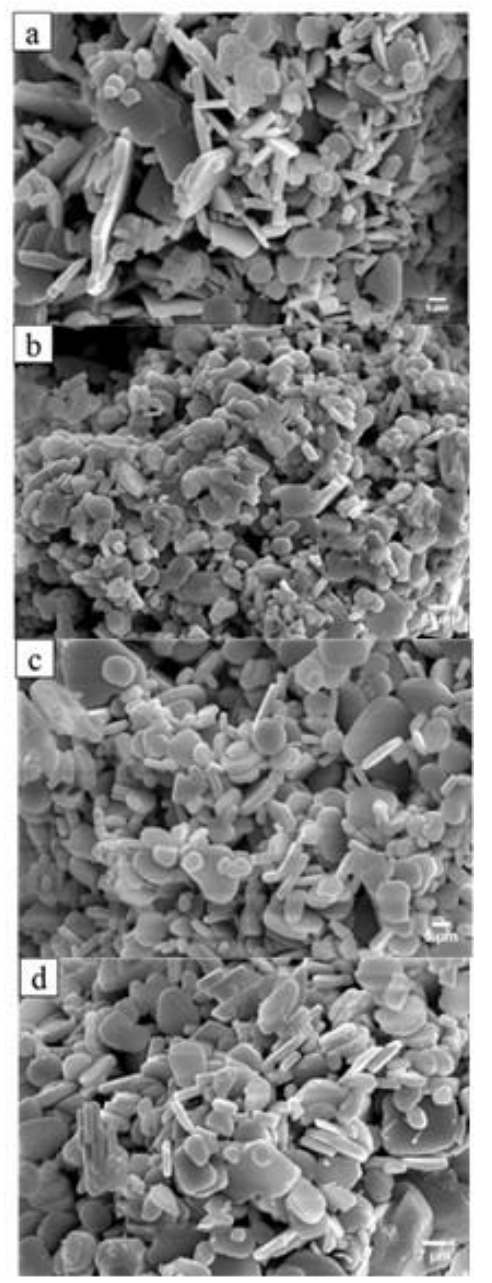

Gambar 3. Mikrograf SEM Bi $\mathrm{Ti}_{3-x} \mathrm{~V}_{x} \mathrm{O}_{12}$ (a) $x=0$, (b) $x=0,05$, (c) $x=0,1$ (d) $x=0,15$, dan (e) $x=0,2$
Mikrograf SEM sampel ditampilkan pada Gambar 3 dan dapat dilihat bahwa morfologi partikel senyawa $\mathrm{Bi}_{4} \mathrm{Ti}_{3-x} \mathrm{~V}_{x} \mathrm{O}_{12}(x=0,0,05 ; 0,1$; 0,15 dan 0,2) berbentuk plate-like atau lempengan. Hal ini sama dengan yang dilaporkan beberapa pihak lain pada penelitian terdahulu $[8,9]$. Hasil mikrograf juga menunjukkan bahwa tidak terbentuk aglomerasi.

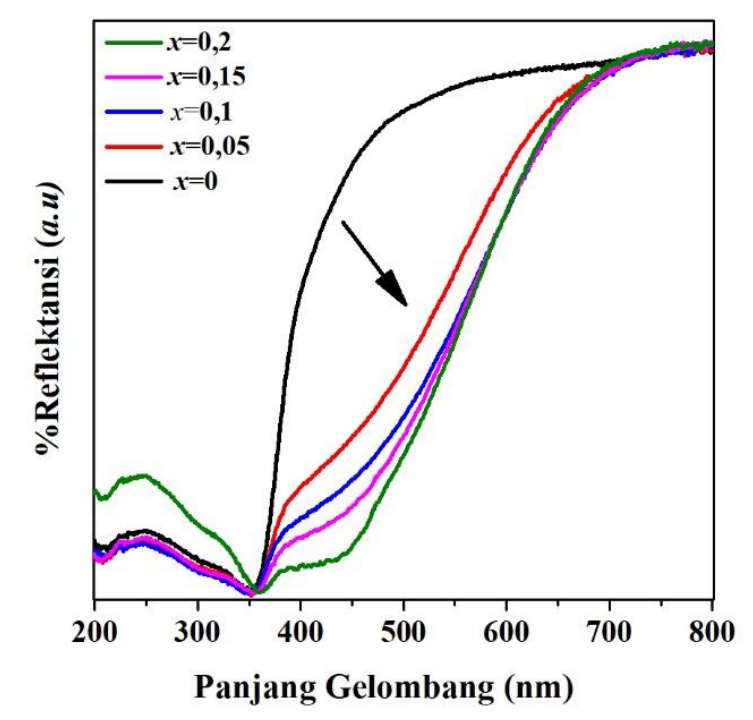

Gambar 4. Spektra UV-Vis DRS $\mathrm{Bi}_{4} \mathrm{Ti}_{3-x} \mathrm{~V}_{x} \mathrm{O}_{12}$ $(x=0,0,05 ; 0,1 ; 0,15$; dan 0,2) (\% reflektansi versus panjang gelombang)

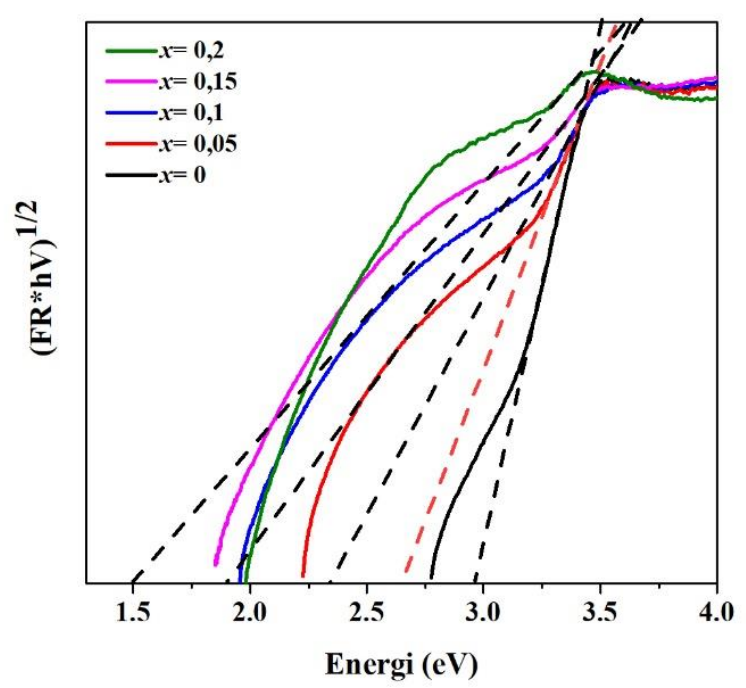

Gambar 5. Hubungan antara $(F R * h v)^{1 / 2}$ dengan energi celah pita $(h v)$

Spektra UV-Vis DRS sampel dan gambar analisis energi celah dengan menggunakan persamaan Kubelka-Munk ditampilkan pada Gambar 4 dan 5. Gambar 4 menunjukkan bahwa persen reflektansi pada sampel terdoping 
vanadium mengalami penurunan dan bergeser ke arah sinar tampak (pergeseran merah). Energi celah hasil perhitungan dengan menggunakan persamaan Kubelka-Munk ditampilkan pada Tabel 1. Dari nilai energi celah dapat diketahui bahwa pendopingan dengan vanadium dapat menurunkan energi celah. Jika vanadium berhasil didoping maka penurunan ini akibat dari pembentukan keadaan baru pita konduksi dari vanadium, sedangkan pada sampel ini masih ditemukan pengotor sehingga mekanisme yang menyebabkan masih belum jelas. Hasil ini juga konsisten dari hasil penelitian Handayani, dkk., (2019) yang mendoping senyawa $\mathrm{Bi}_{4} \mathrm{Ti}_{3} \mathrm{O}_{12}$ dengan logam vanadium dengan metode reaksi keadaan padatan dan juga ditemukan terjadi penurunan nilai energi celah [10]. Takle, dkk., (2018) juga melaporkan terjadi penurunan energi celah pada $\mathrm{TiO}_{2}$ terdoping vanadium yang diakibatkan karena keberadaan $\mathrm{V}^{4+}$ dan $\mathrm{V}^{5+}$ pada kisi $\mathrm{TiO}_{2}$ [11].

Tabel 1. Enegi celah $\mathrm{Bi}_{4} \mathrm{Ti}_{3-x} \mathrm{~V}_{x} \mathrm{O}_{12}(x=0,0,05$; 0,$1 ; 0,15 ;$ dan 0,2 )

\begin{tabular}{ccc}
\hline Sampel & $\begin{array}{c}\text { Energi celah } \\
(\mathrm{eV})\end{array}$ & $\begin{array}{c}\text { Panjang } \\
\text { gelombang }(\mathrm{nm})\end{array}$ \\
\hline$x=0$ & 2,91 & 426 \\
$x=0,05$ & 2,53 & 490 \\
$x=0,1$ & 2,02 & 613 \\
$x=0,15$ & 1,98 & 626 \\
$x=0,2$ & 1,50 & 826 \\
\hline
\end{tabular}

\section{Kesimpulan}

Sintesis senyawa $\mathrm{Bi}_{4} \mathrm{Ti}_{3-x} \mathrm{~V}_{x} \mathrm{O}_{12}(x=0,0,05$; 0,$1 ; 0,15$; dan 0,2 ) dengan metode lelehan garam tunggal $\mathrm{NaCl}$ menghasilkan senyawa $\mathrm{Bi}_{4} \mathrm{Ti}_{3} \mathrm{O}_{12}$ yang terdoping vanadium dan masih mengandung senyawa pengotor $\mathrm{BiNaO}_{3}$ dan $\mathrm{NaV}_{6} \mathrm{O}_{11}$. Nilai energi celah $\mathrm{Bi}_{4} \mathrm{Ti}_{3} \mathrm{O}_{12}$ terdoping vanadium lebih rendah dibandingkan dengan senyawa murninya.

\section{Ucapan Terima Kasih}

Penelitian ini dibiaya melalui skema bantuan Program Penelitian Pengembangan Program Studi, 2018, Lembaga Penelitian dan Pengabdian Masyarakat, Universitas Islam Negeri Maulana Malik Ibrahim Malang.

\section{Daftar Pustaka}

[1] Wang W, Tadé MO, Shao Z. Research progress of perovskite materials in photocatalysis- and photovoltaics-related energy conversion and environmental treatment. Chem Soc Rev. 2015.
44(15):5371-408.

http://dx.doi.org/10.1039/c5cs00113g

[2] Liu Y, Zhu G, Gao J, Hojamberdiev M, Zhu $\mathrm{R}$, Wei $\mathrm{X}$, et al. Enhanced photocatalytic activity of Bi4Ti3O12 nanosheets by $\mathrm{Fe} 3+-$ doping and the addition of Au nanoparticles: Photodegradation of Phenol and bisphenol A. Appl Catal B Environ. 2017. 200:72-82. http://dx.doi.org/10.1016/j.apcatb.2016.06.0 69

[3] Xia A, Tan G, Ren H. Effect of Fe substitution on microstructure and properties of bismuth titanate thin films. Ceram Int. $2016 . \quad 42(1): 1267-71$. http://dx.doi.org/10.1016/j.ceramint.2015.09 .061

[4] Chen Z, Jiang X, Zhu C, Shi C. Chromiummodified $\mathrm{Bi} 4$ Ti 3 O 12 photocatalyst: Application for hydrogen evolution and pollutant degradation. Appl Catal B Environ. 2016.

199:241-51. http://dx.doi.org/10.1016/j.apcatb.2016.06.0 36

[5] Gu D, Qin Y, Wen Y, Li T, Qin L, Seo HJ. Electronic structure and optical properties of V-doped Bi4Ti3O12 nanoparticles. J Alloys Compd. $2017 . \quad 695: 2224-31$. http://dx.doi.org/10.1016/j.jallcom.2016.11. 071

[6] He R, Xu D, Cheng B, Yu J, Ho W. Review on nanoscale Bi-based photocatalysts. Nanoscale Horizons. 2018. 3(5):464-504. http://dx.doi.org/10.1039/c8nh00062j

[7] Xue P, Wu H, Lu Y, Zhu X. Recent progress in molten salt synthesis of low-dimensional perovskite oxide nanostructures, structural characterization, properties, and functional applications: A review. J Mater Sci Technol. $2018 . \quad 34(6): 914-30$. http://dx.doi.org/10.1016/j.jmst.2017.10.005

[8] Zhao W, Jia Z, Lei E, Wang L, Li Z, Dai Y. Photocatalytic degradation efficacy of Bi4Ti3O12 micro-scale platelets over methylene blue under visible light. $J$ Phys Chem Solids. 2013. 74(11):1604-7. http://dx.doi.org/10.1016/j.jpcs.2013.06.003

[9] Januari T, Aini N, Barroroh H, Prasetyo A. The effect of synthesis time to particle size of Bi4Ti3O12 which synthesized using molten single salt $\mathrm{NaCl}$ method. IOP Conf Ser Earth Environ Sci. $2020 . \quad 456: 12013$. http://dx.doi.org/10.1088/17551315/456/1/012013

[10] Handayani R, Safitri WN, Aini N, Hardian A, Prasetyo A. Synthesis and characterization of 
vanadium doped Bi4Ti3O12 as photocatalyst material. IOP Conf Ser Mater Sci Eng. 2019. 578:12017. http://dx.doi.org/10.1088/1757899x/578/1/012017

[11] Takle SP, Naik SD, Khore SK, Ohwal SA,
Bhujbal NM, Landge SL, et al. Photodegradation of spent wash, a sugar industry waste, using vanadium-doped $\mathrm{TiO} 2$ nanoparticles. $R S C A d v$. 2018. 8(36):20394405. http://dx.doi.org/10.1039/c8ra02869a 
Agustina, K. R., et al./J. Kartika Kimia, Mei 2020, 3, (1), 19-24 